\title{
PRONATEC: AMPLIAÇÃO DAS AÇÕES FRAGMENTÁRIAS E INTENSIFICAÇÃO DA PRIVATIZAÇÃO DA FORMAÇÃO DO TRABALHADOR ${ }^{1}$
}

\author{
Jaqueline Pereira Ventura² \\ Ludmila Lustosa Lessa ${ }^{3}$ \\ Samantha Castro V. de Souza ${ }^{4}$
}

\begin{abstract}
Resumo
Este estudo objetiva analisar o Programa Nacional de Acesso ao Ensino Técnico e Emprego (Pronatec), especialmente a sua iniciativa Bolsa-Formação, tomando por base os documentos oficiais do programa no período entre 2011 e 2013. Apresenta o que é e como está estruturado o Pronatec, bem como sua amplitude e seu alcance. Discute, também, as implicações políticas do tipo de qualificação profissional priorizada nesse programa com o esforço de análise de seus limites e suas contradições. O texto conclui que as ações do Pronatec intensificam o processo de privatização da formação do trabalhador.
\end{abstract}

Palavras-chave: Educação Profissional; Pronatec; Bolsa-formação.

\section{Resumen}

Este estudio busca analizar el Programa Nacional de Acesso ao Ensino Técnico e Emprego (Pronatec), en especial su iniciativa Bolsa-Formação, con base en los documentos oficiales del programa en el período desde 2011 hasta 2013. Esta producción presenta qué es y cómo se estructura el Pronatec, así como su extensión y su alcance. Se discuten, también, las implicaciones políticas del tipo de calificación profesional que se prioriza en ese programa con un esfuerzo de análisis de sus límites y sus contradicciones. El texto concluye que las acciones del Pronatec intensifican el proceso de privatización de la formación del trabajador.

Palabras clave: Educación Profesional; Pronatec; Bolsa-Formação

\section{Introdução}

A história da educação, nos países capitalistas, é caracterizada pela dualidade estrutural da educação, que traça trajetórias escolares diferenciadas

\footnotetext{
${ }^{1}$ DOI: https://doi.org/10.22409/tn.16i30.p10091

${ }^{2}$ Doutora em Educação. Professora da Faculdade de Educação e do Programa de PósGraduação em Educação da Universidade Federal Fluminense (UFF).

${ }_{3}^{3}$ Pedagoga. Professora da rede pública municipal de São Gonçalo/RJ. Mestranda em Educação pela Universidade Federal Fluminense na Linha Trabalho e Educação.

${ }^{4}$ Mestre em Educação. Doutoranda em Educação pela Universidade Federal do Pará na Linha Políticas Públicas Educacionais.
} 
segundo a classe social. No Brasil, essa dualidade se caracterizou por uma formação mais acadêmica e intelectual, destinada às elites, e uma formação mais profissional voltada aos trabalhadores, ainda que em níveis diferenciados de preparação da força de trabalho 4 .

$\mathrm{Na}$ implementação de qualquer projeto educacional (abrangente ou restrito, local ou nacional), a disputa entre projetos antagônicos de sociedade está presente, e o seu desenrolar depende da correlação de forças do Estado ampliado 5 .

As reformas da educação básica na década de 1990 são um marco na implantação e na implementação das políticas neoliberais no Brasil. Essas políticas foram conduzidas no país sob o engodo do caminho único para a inserção competitiva na economia mundial globalizada. $\mathrm{Na}$ realidade, elas restabeleceram, sob novos marcos, a relação de subordinação do país ao capitalimperialismo. E, internamente, construíram e fortaleceram uma sociabilidade fundada num critério único de eficiência, os ditames do mercado: abertura econômica, competitividade e lucratividade.

Com o objetivo de (con)formar atitudes, capacidades, habilidades e competências no conjunto da força de trabalho brasileira, duas características centrais marcaram as reformas educacionais conduzidas pelo viés neoliberal desses organismos multilaterais ${ }^{6}$ : a educação dirigida à formação para o trabalho simples e a educação dirigida à gestão da pobreza (OLIVEIRA, 2000).

\footnotetext{
${ }^{4} \mathrm{O}$ presente texto é constituído por parte de ideias desenvolvidas em VENTURA; LESSA; SOUZA, 2017.

${ }^{5}$ Gramsci conceitua o Estado em sentido amplo, composto de duas esferas principais: a sociedade política (conjunto dos mecanismos através dos quais a classe dominante detém o monopólio legal do controle e da execução das leis) e sociedade civil (conjunto das organizações responsáveis pela elaboração e difusão de concepções de mundo). Nessa noção geral de Estado "seria possível dizer, de que Estado = sociedade política + sociedade civil, isto é, hegemonia couraçada de coerção" (GRAMSCl, 2007, p. 244). Não havendo, portanto, oposição entre essas esferas já que elas se complementam, sem que o Estado perca o seu caráter de classe. Assim, "Enquanto existir o Estado classe não pode existir a sociedade regulada [...] permanece exato o conceito [...] de que não pode existir igualdade política completa e perfeita sem igualdade econômica" (GRAMSCI, 2007, p. 223-224). Na sociedade capitalista, não há espaço para a igualdade política, a não ser do ponto de vista formal e, em consequência do primeiro enunciado, não se estabelecem relações entre iguais, mas sim entre classes sociais fundamentais, desiguais, com interesses antagônicos.

${ }^{6}$ Os organismos multilaterais são instituições internacionais que influenciam nas políticas econômicas e sociais de países de capitalismo dependente como, por exemplo, Fundo Monetário Internacional (FMI), Banco Mundial (BIRD) e Programa das Nações Unidas para o Desenvolvimento (PNUD).
} 
Aliás, muitas das ofertas educacionais de qualificação para o trabalho compõem o emaranhado de ações das políticas de "alívio por gotejamento" (FONTES, 2010, p. 339). Nesse sentido, as disputas incidem diretamente sobre os contornos que deve ter a educação profissional e seus possíveis vínculos com a educação básica.

Desde então, as reformas da educação seguem os interesses do capital de elevar a qualificação da força de trabalho simples, desenvolvendo nela a suposta capacidade competitiva através da empregabilidade ${ }^{7}$ e a flexibilidade de exercer qualquer trabalho independentemente do momento e do lugar (reinventando o trabalhador constantemente). Eles implementam, recorrentemente, precárias políticas focalizadas, financiadas por agências públicas, geridas e executadas por instituições privadas.

Segundo a perspectiva do discurso hegemônico, um dos meios para superar a suposta carência de formação da força de trabalho brasileira, considerada responsável pela não competitividade do Brasil a nível mundial, é a expansão acelerada da qualificação, bem como o acesso a diferentes níveis de certificação.

Essa diretriz tem criado um lucrativo mercado de transferência de recursos públicos para instituições privadas ao expandir as vias formativas de caráter precário e aligeirado na rede privada e ampliar as possibilidades de certificação, realizadas, em sua maioria, com negação do direito ao conhecimento.

Nesse aspecto, ganha centralidade o protagonismo do empresariado na gestão e na execução dessas novas vias formativas, principalmente através da política de parcerias público-privadas com seus programas, projetos e planos em todos os níveis da formação. Aqui, iremos nos debruçar sobre um exemplo que materializa esse processo: o Programa Nacional de Acesso ao Ensino Técnico e Emprego (Pronatec).

O Pronatec, iniciativa adotada pelo Governo Federal referente à educação profissional voltada para jovens e adultos da classe trabalhadora, oferece vagas em cursos de qualificação em todo o país, sob o discurso de que seus cursos

\footnotetext{
${ }^{7}$ A promessa de empregabilidade "encobre o agravamento das desigualdades do capitalismo contemporâneo, deslocando a produção dessa desigualdade da forma que assumem as relações sociais de produção para o plano do fracasso do indivíduo" (FRIGOTTO, 2011, p. 116-117).
} 
aumentariam a qualificação do brasileiro, especialmente da juventude. Embora não se autodenomine assim, o Pronatec tem um caráter emergencial, com ações focais voltadas para uma suposta inclusão social através do aumento das chances de emprego via qualificação profissional.

Nesse sentido, o programa vincula, de forma direta, a política educacional ao desenvolvimento econômico do país e ao acesso à renda para os indivíduos. Reeditando, assim, a teoria do Capital Humano ${ }^{8}$ e a formação humana rebaixada da classe trabalhadora. Essa atuação revela a estratégia dos setores dominantes para (con)formar a classe trabalhadora através de programas educacionais, como o Pronatec.

Esse movimento restringe a educação às necessidades do campo econômico. Tal vínculo, carregado de conteúdo ideológico, consolida um novo tipo de dualidade, no qual o Estado amplia as vias formativas de caráter precário, sob o suposto signo da igualdade de oportunidades.

Desse modo, a nova configuração da dualidade educacional no país referese às "novas formas de destituição do direito de acesso universal às bases do conhecimento científico e tecnológico" (RUMMERT; ALGEBAILE; VENTURA, 2013, p. 722).

Essa expansão da educação vem sendo realizada de forma desigual e combinada, pois não garante o acesso igualitário às bases do conhecimento científico e tecnológico. Essa forma de "dualidade educacional de novo tipo" (RUMMERT; ALGEBAILE; VENTURA, 2013, p. 724) materializa-se nas diferenças entre as diversas redes de ensino público, bem como entre as variadas modalidades e padrões de ofertas na rede privada.

A grande diversificação de ofertas educacionais em formas desiguais e combinadas produz "uma miríade de ofertas de elevação de escolaridade/formação profissional/certificação, fortalecendo as estratégias de subalternidade no contexto da atual fase de desenvolvimento do capitalismo brasileiro" (RUMMERT; ALGEBAILE; VENTURA, 2013, p. 724).

O que marca essa nova dualidade é justamente a produção de uma multiplicidade de oportunidades educativas, porém, de forma subordinada,

\footnotetext{
${ }^{8}$ A análise crítica da Teoria do Capital Humano nos é apresentada por Frigotto (1993).
} 
ampliando o acesso a todos os níveis de certificação sem universalizar padrões socialmente referenciados.

O foco desta análise é o desvelamento das contradições presentes no programa, assim como a sua intenção em priorizar a oferta de vagas em cursos de curta duração, oferecidos majoritariamente pela rede privada. Situação que converge com a intensificação do processo de privatização da educação profissional.

Organizamos o estudo em duas seções. Na primeira, O que é o Pronatec: definição e caracterização do Programa, compilamos o amplo conjunto de documentos relacionados ao programa. Nesse percurso, tomamos por base seus documentos oficiais, apresentando o que é e como está estruturado o Pronatec, bem como sua amplitude e alcance atual.

$\mathrm{Na}$ segunda seção, Limites do Pronatec: fragmentação e privatização do Programa, revelamos as implicações políticas e os limites do tipo de qualificação profissional que é priorizada nesse programa. Pretendemos demonstrar, assim, que o Pronatec, principalmente através da modalidade Bolsa-Formação, acentua a fragmentação e a privatização, por meio do apoio à oferta de cursos no âmbito privado.

\section{O que é o Pronatec: definição e caracterização do Programa}

O Programa Nacional de Acesso ao Ensino Técnico e Emprego (Pronatec) foi criado com a implementação da lei no 12.513 , de 26 de outubro de 2011. Seus principais objetivos são: expandir, interiorizar e democratizar a educação profissional, ampliando o número de vagas nos cursos de educação profissional técnica de nível médio presencial e a distância e de cursos de formação inicial e continuada ou qualificação profissional; promover a expansão da rede física da educação profissional e tecnológica; contribuir para a melhoria da qualidade do Ensino Médio, por meio da articulação com a educação profissional; ampliar as oportunidades educacionais dos trabalhadores com o incremento da formação e da qualificação profissional; e apoiar a oferta de cursos de educação profissional e tecnológica com estímulo à produção de recursos pedagógicos (BRASIL, 2011). 
Esse programa atende, prioritariamente, estudantes ou egressos do Ensino Médio público que tenham sido bolsistas integrais na rede privada, no regular e na modalidade de Educação de Jovens e Adultos (EJA). E, também, trabalhadores do campo (agricultores familiares, silvicultores, aquicultores, extrativistas e pescadores), desempregados, beneficiários dos programas de transferência de renda do Governo Federal, povos indígenas, quilombolas, adolescentes e jovens em cumprimento de medidas socioeducativas (em regime aberto, semiaberto ou fechado) e pessoas com deficiência, garantindo as condições de acessibilidade aos recursos pedagógicos e à estrutura física do local (BRASIL, 2011).

Para alcançar seus objetivos e seu público-alvo, o Pronatec oferece 864 opções de cursos. São 220 na modalidade técnica de nível médio, com durações que variam de 800 a 1.200 horas, e 644 na modalidade de formação inicial e continuada, que variam de 160 a 400 horas de duração. Ambos são divididos em 13 eixos tecnológicos ${ }^{9}$ de acordo com o Catálogo Nacional de Cursos Técnicos de Nível Médio e o Guia Pronatec de Cursos FIC.

Os cursos técnicos de nível médio devem ocorrer de forma articulada com o Ensino Médio, seguindo as orientações dispostas no decreto $5.154 / 2004^{10}$ (BRASIL, 2004). Eles podem ser integrados ao Ensino Médio, ou seja, na mesma instituição de ensino, em matrícula única, correspondendo ao Ensino Médio e ao curso técnico; concomitantes, podendo ser oferecidos pela mesma instituição ou por outra, diferente daquela que esteja oferecendo o Ensino Médio - nesse caso, o aluno terá duas matrículas -; ou subsequentes, oferecidos somente a quem já tenha concluído o Ensino Médio.

Os Cursos de Formação Inicial e Continuada (FIC) destinam-se à qualificação profissional ou à formação de habilidades iniciais, especialmente para aqueles jovens e adultos trabalhadores que ainda não terminaram a educação básica. Têm como principais objetivos proporcionar o desenvolvimento de

\footnotetext{
${ }^{9}$ Os 13 eixos tecnológicos dos cursos do Pronatec são: Ambiente e Saúde; Controle e Processos Industriais; Desenvolvimento Educacional e Social; Gestão e Negócios; Informação e Comunicação; Infraestrutura; Militar; Produção Alimentícia; Produção Cultural e Design; Produção Industrial; Recursos Naturais; Segurança; Turismo, Hospitalidade e Lazer. Disponível em: $<$ http://Pronatec.mec.gov.br/>. Acesso em: 23 fev. 2018.

10 "Decreto $n^{\circ} 5.154$, de 23 de julho de 2004 , regulamenta o $\S 2^{\circ}$ do art. 36 e os arts. 39 a 41 da lei no 9.394, de 20 de dezembro de 1996, que estabelece as diretrizes e bases da educação nacional e dá outras providências" (BRASIL, 2004).
} 
aptidões para a vida produtiva e social, promovendo a capacitação, o aperfeiçoamento e a especialização em determinada área.

É importante ressaltar que a lei no 12.513/2011 (BRASIL, 2011), que instituiu o Pronatec, efetivou quatro grandes alterações em leis anteriores. A primeira alteração dispõe sobre a lei no 7.998, de 11 de janeiro de 1990, que regula o Programa Seguro Desemprego, o Abono Salarial e institui o Fundo de Amparo ao Trabalhador (FAT) (BRASIL, 1990).

Com a criação do Pronatec, o recebimento do seguro-desemprego tornouse condicionado à matrícula e à frequência num curso de qualificação com carga horária mínima de 160 horas, oferecido pelo Pronatec gratuitamente aos trabalhadores dispensados sem justa causa. Em caso de recusa em matricularse, o trabalhador terá seu benefício cancelado (BRASIL, 2011).

Entretanto, a obrigatoriedade de participação no Pronatec em cursos de qualificação não contribui efetivamente para a reinserção desses profissionais no mercado de trabalho, sobretudo, quando eles realizam um curso numa área diferente daquela em que tiveram suas experiências profissionais.

A segunda alteração refere-se ao art. 28 da lei no 8.212, de 24 de julho de 1991, que dispõe sobre a organização da Seguridade Social e institui o Plano de Custeio, incidindo sobre o Salário-de-Contribuição (BRASIL, 1991).

A referida lei permitia que os trabalhadores financiassem sua qualificação profissional através de um empréstimo chamado Plano Educacional, desde que o curso de formação estivesse vinculado às atividades desenvolvidas pela empresa. Em contrapartida, o trabalhador deveria pagar uma parcela mensal (não superior a 5\%), a ser descontada de sua remuneração.

Com a instituição do Pronatec, além do Plano Educacional, abre-se a possibilidade de essa qualificação profissional ser realizada por meio de bolsas de estudos que podem ser financiadas pela empresa. Cabe ressaltar que os valores relativos ao Plano Educacional ou às Bolsas não integram o Salário-deContribuição, por isso eles não são repassados à Previdência Social e não podem ser requeridos em caso de incapacidade provisória ou permanente do trabalhador (BRASIL, 2011).

A terceira alteração incide sobre a lei no 10.260, de 12 de julho de 2001, que regulamenta o Fundo de Financiamento ao Estudante do Ensino Superior. 
(BRASIL, 2001). Com a criação do Pronatec, a destinação da concessão do financiamento foi estendida aos cursos de formação inicial e continuada ou de qualificação profissional e aos cursos de educação profissional técnica de nível médio, passando a denominar-se apenas Fundo de Financiamento Estudantil (Fies).

O Fies é dividido em duas modalidades: Fies-Técnico, correspondente ao financiamento individual concedido ao estudante para custear cursos de nível superior e/ou cursos de educação profissional; e Fies-Empresa, financiamento concedido às empresas para custearem os cursos de qualificação de seus funcionários na rede privada ou no próprio local de trabalho por meio de parcerias com outras empresas (BRASIL, 2011). Esse financiamento poderá chegar a 100\% dos valores cobrados aos estudantes e empresários, ambos com a taxa de juros de $3,4 \%$ ao ano (BRASIL, 2001).

Quanto a essa questão, além das vantagens já citadas, também constatamos que os empresários se beneficiam triplamente com os recursos públicos. Primeiro, por terem, por parte do Estado, o abatimento do investimento efetuado em programas de treinamento que já realizavam. Segundo, por utilizarem o financiamento para pagar a qualificação dos seus próprios empregados. Terceiro, pelo incentivo à oferta da educação-mercadoria ${ }^{11}$. O Estado contribui, dessa forma, para a intensificação do mercado da educação.

A última alteração foi realizada sobre a lei oㅜ 11.129, de 30 de junho de 2005, que instituiu o Programa Nacional de Inclusão de Jovens (Projovem) (BRASIL, 2005). As alterações efetivadas nesse programa referem-se à inclusão do Programa de Bolsas para a Educação pelo Trabalho, destinado aos estudantes de educação superior, prioritariamente com idade inferior a 29 anos, e aos trabalhadores da área da saúde.

Tendo em vista a ampliação da sua proposta original, das estratégias de execução e dos recursos empreendidos, organizamos a análise do programa em

\footnotetext{
${ }^{11}$ Para Rodrigues (2007), existem duas formas básicas de os empresários encararem esse mercado educacional. A primeira, educação-mercadoria, ocorre quando o capital empresarial cresce através da venda de serviços educacionais. Nesse caso, os apropriadores desse capital são os empresários do comércio educacional. A segunda forma se efetiva quando a educação e o conhecimento são tidos como insumos necessários e indispensáveis à produção de novas mercadorias. Nesse caso, são os empresários industriais que se apropriam da mercadoriaeducação para ampliar seus capitais.
} 
três aspectos: 1.1. As ações, 1.2. Os Agentes e 1.3. As Modalidades de Demandas. Nesse percurso de análise, tomando por base os documentos oficiais do programa, iremos apresentá-lo intentando evidenciar sua amplitude e alcance.

\subsection{As ações}

O Pronatec está vinculado à Secretaria de Educação Profissional e Tecnológica (SETEC), é estruturado pelo Ministério da Educação (MEC) e articula-se com o Sistema Nacional de Emprego (SINE) do Ministério do Trabalho e Emprego (MTE), com a finalidade de desenvolver nove ações.

Contudo, os relatórios disponibilizados pela SETEC evidenciam apenas seis ações, são elas: fortalecimento e expansão da Rede Federal de Educação Profissional, Científica e Tecnológica (REPCT); Rede e-TEC Brasil (expansão da educação profissional na modalidade a distância); Brasil Profissionalizado (fomenta a expansão da educação profissional integrada ao ensino médio nas redes estaduais de educação).

Também: Fundo de Financiamento Estudantil (Fies técnico e empresa, que visa financiar cursos de nível superior e profissional em escolas privadas, no Sistema $S$ ou no próprio local de trabalho, por meio de parcerias com as empresas); Acordo Gratuidade com o Sistema $S$ (prevê a conversão da contribuição compulsória dessas instituições em cursos gratuitos). E, ainda, Bolsa Formação (Estudante e Trabalhador, que é um recurso utilizado para custear as matrículas e as despesas com alimentação e transporte dos alunos), um dos principais eixos de sustentação para desenvolvimento do programa, conforme será visto na segunda seção deste trabalho.

\subsection{Os agentes}

Participam como agentes das ações do Pronatec a Secretaria de Educação Profissional e Tecnológica (SETEC), o Fundo Nacional de Desenvolvimento da Educação (FNDE) e os parceiros ofertantes e demandantes dos cursos do programa. 
A SETEC é responsável por coordenar e avaliar as políticas de educação profissional em geral e a oferta da Bolsa-Formação. É ela quem solicita ao FNDE $^{12}$ o repasse de recursos para os parceiros ofertantes das Bolsas.

Os parceiros ofertantes são todas as redes de ensino (privadas e públicas) que queiram participar da gestão do programa, sendo responsáveis pela oferta dos cursos, mediante uma atuação conjunta com os parceiros demandantes.

As instituições privadas passaram a integrar o rol das instituições ofertantes dos cursos após a aprovação da medida provisória 593, de 05 de dezembro de 2012 (BRASIL, 2012a), posteriormente transformada na lei $n^{-}$ 12.816, de 05 de junho de 2013, que "amplia o rol de beneficiários e de ofertantes do Bolsa-Formação Estudante no âmbito do Pronatec" (BRASIL, 2013b).

Com relação à parceria público-privada, no $\S 1^{\circ}$ do art. $6-\mathrm{A}$, a referida lei autoriza a abertura de cursos do programa na rede privada de Ensino Superior e de educação profissional técnica de nível médio, por meio de um termo de adesão realizado entre a SETEC e as instituições ofertantes (BRASIL, 2013b).

Faz-se necessário esclarecer que esse termo de adesão não estabelece critérios, normas ou qualquer tipo de padrão de qualidade dos serviços, "não há prazos de vigência para cumprimento do termo nem cláusulas estabelecendo punições" (BRASIL, 2013e, p. 31), as instituições só precisam garantir aos beneficiários do programa o acesso às vagas gratuitas, com o compromisso de prestar contas das matrículas realizadas.

Nessa direção, cabe ressaltar, ainda, que o Pronatec concedeu autonomia pedagógica de criação de cursos a todas as unidades ofertantes. Integrou os serviços nacionais de aprendizagem ao sistema federal de ensino, sob a disciplina dos critérios do MEC, conferindo autonomia às unidades dos serviços nacionais sociais para ofertarem cursos de

educação profissional técnica de nível médio e educação de jovens e adultos integrada à educação profissional, desde que em articulação direta com os serviços nacionais de aprendizagem, observada a competência de supervisão e avaliação dos Estados. (BRASIL, 2013b).

\footnotetext{
${ }^{12}$ O FNDE é o órgão responsável pelo repasse dos recursos financeiros às instituições ofertantes dos cursos. O repasse é concedido no valor do custo total do curso por estudante de acordo com o número de alunos matriculados e a carga horária por curso ministrado (BRASIL, 2013d).
} 
Os demandantes são os entes públicos (ministérios, secretarias estaduais e órgãos públicos da Casa Civil) responsáveis por identificar a demanda, bem como o curso de qualificação profissional que atenda ao público-alvo de suas ações, assim como a divulgação, a inscrição, a seleção e as pré-matrículas de seus beneficiários.

Os cursos são classificados por modalidades de demandas pela SETEC como uma forma de facilitar a seleção do público-alvo de acordo com a especificidade de cada demandante. É importante ressaltar que, quando o demandante define um público-alvo como prioridade, assume a responsabilidade de criar mecanismos que favoreçam a sua seleção.

\subsection{Modalidades de demandas}

Segundo o Relatório de Auditoria Anual de Contas, foi registrada, em 2013, a participação de 55 parceiros demandantes, entre eles, 13 ministérios, 6 secretarias vinculadas à União e 26 secretarias estaduais de educação, além do Distrito Federal. Juntos, oferecem 41 modalidades de demandas ${ }^{13}$ no âmbito da Bolsa-Formação Estudante e Trabalhador. Realizada por meio de uma parceria entre o MEC e diferentes ministérios e secretarias, a parceria teve como objetivo atender a diversos grupos sociais.

Devido às variações de estrutura e de níveis de conhecimento, a organização do Pronatec com suas diversas modalidades contribui para produzir uma nova dualidade entre as instituições participantes e seus parceiros demandantes.

Isso acarretou a fragmentação do programa em variados tipos de estrutura física, currículo e processo de seleção, em função dos diferentes perfis de público e de instituições participantes como: Organizações Não Governamentais (ONGs); instituições públicas de ensino de formação inicial e continuada, técnico e tecnológico; instituições privadas de ensino; e Sistema S.

\footnotetext{
${ }^{13} \mathrm{O}$ termo modalidade(s) é utilizado pelo MEC para referir-se aos cursos, às Bolsas-Formação e aos subprogramas ofertados pelo Pronatec. No que tange aos cursos, eles se dividem em modalidade técnica de nível médio e modalidade de formação inicial e continuada. Quanto às Bolsas-Formação, elas se organizam nas modalidades da Bolsa-Formação Estudante e da BolsaFormação Trabalhador. Utilizaremos, aqui, o termo subprogramas como sinônimo do termo modalidades de demandas.
} 
Assim sendo, além dos parceiros ofertantes, os parceiros demandantes também passam a ter autonomia para criar, coordenar e administrar financeiramente suas respectivas modalidades do programa. A nosso ver, essa forma de gestão acaba por beneficiar e fortalecer especialmente a iniciativa privada, que passa a ter autonomia para criar e ofertar o modelo de formação que atenda aos seus interesses imediatos.

Até aqui, discorremos sobre os ordenamentos legais do programa, sua estrutura organizativa, seus objetivos, suas ações, seus agentes e suas modalidades de demandas. Na próxima seção, submeteremos à crítica 0 Pronatec, última política de expansão da educação profissional adotada durante o governo Dilma Rousseff.

\section{Limites do Pronatec: fragmentação e privatização}

O Pronatec, assim como os demais programas, surge sob a justificativa da necessidade de expansão das vias formativas e das possibilidades de acesso a todos os níveis de certificação. A principal ênfase desses programas está nos cursos de formação inicial e continuada, cursos de curta duração, em detrimento daqueles de formação técnica de nível médio que possuem maior duração.

O Pronatec aparece como resposta a uma suposta deficiência de força de trabalho qualificada - discurso hegemônico que atribui à educação a responsabilidade das dificuldades encontradas pela economia brasileira em desenvolver sua competitividade a nível mundial.

Esse movimento impõe à educação um vínculo restrito com as necessidades do campo econômico, em conformidade com a função social que a educação assume para as classes dominantes: a de produzir ganhos adicionais ao capital.

Nesse cenário, a crise de empregos torna-se um problema individual. E essa contradição abre, por um lado, cada vez mais canais de empresariamento da educação, já que a procura por qualificação se eleva; por outro lado, escamoteia o fato de que não há, efetivamente, empregos para todos, pois o desemprego é um problema inerente ao capital. 
Numa análise superficial dos ordenamentos legais do Pronatec, poderíamos dizer que as críticas realizadas sobre o aligeiramento da qualificação dos jovens e adultos trabalhadores podem ser ou foram superadas. Aparentemente, o Pronatec se diferencia dos demais programas por ofertar também cursos técnicos de longa duração (800 a 1200 horas) em comparação aos cursos FIC (160 a 400 horas), especialmente pela possibilidade de esses cursos técnicos serem realizados de forma integrada ao Ensino Médio.

No entanto, de acordo com os dados divulgados pela SETEC em novembro de 2014, o programa já teria formado, até agosto do mesmo ano, mais de 8 milhões de jovens e adultos trabalhadores por todo o Brasil. Sendo 5,8 milhões nos cursos de formação inicial e continuada e 2,3 milhões nos cursos técnicos de nível médio (BRASIL, 2015).

Com bases nos mesmo dados da SETEC/2014 apresentados no parágrafo anterior, podemos concluir que, dos oito milhões de matrículas realizadas pelo Pronatec, houve uma predominância delas nos cursos FIC, ou seja, mais de $70 \%$ do total das matrículas foram realizadas em cursos de curta duração, dos quais 58\% possuem duração mínima de 160 horas.

Para Frigotto, Ciavatta e Ramos (2005, p. 1098), "limitar a carga horária a um 'máximo' é, na verdade, admitir que aos jovens e adultos trabalhadores se pode proporcionar uma formação 'mínima'". Apesar de o Pronatec ofertar cursos FIC com carga horária de até 400 horas, duração bem superior se comparada com a dos programas de qualificação profissional dos governos anteriores, esse modelo de formação, por não exigir uma qualificação complexa ${ }^{14}$, faz com que os jovens e adultos trabalhadores "não estejam preparados nem para as exigências profissionais, nem para o exercício autônomo da cidadania" (FRIGOTTO, 2007, p. 1140).

Essa lógica ainda é mais crítica quando se observa, nos cursos técnicos de nível médio, a predominância de matrículas na modalidade concomitante realizadas por instituições privadas e pelo Serviço Nacional de Aprendizagem

\footnotetext{
${ }^{14}$ Dos 644 cursos, 420 exigem apenas o Ensino Fundamental incompleto, isso equivale a $65,22 \%$ do total da oferta de vagas. Desse quantitativo, $47 \%$ determinam que se tenha no mínimo o Ensino Fundamental I incompleto, enquanto $18 \%$ da oferta exige a conclusão mínima de um ano de estudo no Ensino Fundamental I. Comprovadamente, os cursos que requisitam o Ensino Médio completo representam apenas $0,8 \%$ do total da oferta (BRASIL, 2013c).
} 
(SNA). A concomitância resulta na redução das possibilidades de os jovens e adultos trabalhadores realizarem esses cursos, pois implica assumir a responsabilidade por uma tripla jornada (Ensino Médio/curso técnico/trabalho) (MELO; MOURA, 2016).

Através do número de matrículas, pode-se perceber que os cursos FIC encontram grande receptividade por parte dos jovens e adultos trabalhadores. A predominância dessa modalidade pode ser explicada, por exemplo, por questões como: I) a possibilidade do recebimento de uma assistência estudantil realizada por meio da Bolsa-Formação; II) o condicionamento do Programa Seguro Desemprego ao programa; III) a baixa ou a quase inexistência de exigências de escolaridade para a realização dos cursos; IV) a grande diversidade de opções de cursos; V) os cursos de curta duração; e VI) a possibilidade de (re)inserção no mercado de trabalho e de mobilidade social por meio da ampliação individual da qualificação.

Contudo, entre as questões citadas, iremos nos deter, nesta seção, aos limites do tipo de qualificação profissional que é priorizada pelo programa por meio da modalidade Bolsa-Formação.

A peculiaridade do Pronatec é a Bolsa-Formação, regulamentada pela portaria $n^{\circ}$ 168, de 07 de março de 2013. Tem a finalidade de contribuir para a expansão da oferta da educação profissional, por meio da compra de vagas presenciais e a distância em instituições vinculadas às Redes Federal, Estadual e Municipal, às unidades dos Sistemas Nacionais de Aprendizagem (SNA) e à Rede Privada (escolas técnicas de nível médio e instituições de Ensino Superior) (BRASIL, 2013d).

Nesse documento, são apresentadas duas modalidades de Bolsa. A primeira, intitulada Bolsa-Formação Estudante, está vinculada à oferta de cursos técnicos de educação profissional em nível médio. Essa Bolsa pode ser ofertada de forma concomitante aos estudantes em idade própria, regularmente matriculados no Ensino Médio, e de forma concomitante ou integrada aos estudantes com idade igual ou superior a 18 anos e àqueles pertencentes à modalidade de Educação de Jovens e Adultos que não tenham concluído o Ensino Médio. Além da forma subsequente aos concluintes, desde que tenham 
cursado o Ensino Médio completamente na rede pública ou como bolsistas integrais em instituições privadas.

A segunda modalidade é a Bolsa-Formação Trabalhador, que tem como iniciativa "a oferta gratuita de cursos de formação inicial e continuada ou qualificação profissional destinados a trabalhadores de diferentes perfis e beneficiários de programas federais de transferência de renda e estudantes de Ensino Médio das redes públicas" (BRASIL, 2012b, p. 8). Segundo a portaria ํo 185/2012, também poderá ser concedida a Bolsa-Formação Trabalhador aos estudantes do Ensino Médio público inseridos nos cursos FIC (BRASIL, 2012c).

Os valores repassados por meio da Bolsa-Formação aos parceiros demandantes deverão financiar todas as despesas com vagas, materiais didáticos e assistência estudantil para os alunos custearem seu transporte e sua alimentação.

Os valores recebidos pelos estudantes por meio da assistência estudantil serão garantidos pelo fornecimento direto do parceiro ofertante ou por terceiros que tenham sido contratados. Cabe ressaltar que esse benefício estudantil aplicase somente aos cursos de formação inicial e continuada, aos cursos técnicos na forma integrada, na modalidade EJA, concomitante, não contemplando a forma subsequente, conforme a portaria no 114, de 7 de fevereiro de 2014 (BRASIL, 2014).

A Bolsa-Formação "consiste na combinação de oferta educacional com a contrapartida de um 'benefício' em dinheiro. Entendida como forma de manter o aluno no curso, paradoxalmente, a bolsa funciona como forma de atrair o aluno para o curso" (SILVA, L., 2014, p. 189). Apesar de esta ser uma ação particular do Pronatec, a iniciativa da oferta de bolsas no âmbito da política educacional mantém características assistencialistas vinculadas às políticas sociais.

A possibilidade de receber o auxílio estudantil por meio da bolsa influencia os jovens e adultos da classe trabalhadora a realizarem uma infinidade de cursos aligeirados, em áreas diferentes daquelas em que adquiriram sua experiência profissional. Tudo isso com uma expectativa de inserção ou retorno ao mercado de trabalho.

Como forma de controlar a oferta e o recebimento desse auxílio, cada beneficiário poderá realizar até três matrículas por ano, sendo apenas uma 
matrícula na modalidade técnico de nível médio, não podendo ser realizada de forma concomitante (SILVA, M., 2015). Assim, o auxílio financeiro funciona como um potencializador da conformação social da classe trabalhadora ao gerar uma expectativa de emprego futuro e de inclusão social por meio do aumento da qualificação profissional.

O tipo de curso e o número de vagas ofertados nas modalidades da BolsaFormação são definidos pelos parceiros ofertantes e demandantes controlados pelo Sistema Nacional de Informação da Educação Profissional e Tecnológico (SISTEC), órgão responsável por registrar as informações sobre a educação profissional no país.

O sistema exige dos parceiros ofertantes um cadastro do portfólio dos cursos FIC e Técnico que estejam aptos a ofertar, além disso, a SISTEC classificou as Bolsas-Formação por tipo de modalidade de demanda, com o objetivo de identificar os demandantes de acordo com a característica do públicoalvo.

Através desse sistema, os parceiros demandantes realizam o processo de ocupação, seleção e pré-matrículas das vagas nos cursos FIC e Técnico concomitante, ofertados aos jovens e adultos trabalhadores por eles selecionados.

Para obter acesso às vagas gratuitas dos cursos técnicos na forma subsequente do Pronatec, os interessados devem participar do Exame Nacional do Ensino Médio (ENEM). A seleção do estudante é realizada mediante o resultado dessa avaliação. Ele deve se inscrever no curso da instituição que desejar, através do Sistema de Seleção Unificada da Educação Profissional e Tecnológica (SISUTEC).

A definição de quais cursos técnicos e de formação inicial e continuada serão ofertados pelo programa é elaborada a partir de um mapeamento realizado pelos parceiros demandantes sobre um levantamento do perfil socioeconômico local, que indica o tipo de curso e o perfil dos interessados que seja compatível com as demandas do setor empresarial (SANTOS, 2014).

O status prioritário do setor empresarial pode ser observado para além das suas demandas com mão de obra qualificada, pois foi um beneficiário dos 
recursos públicos recebidos por meio da oferta de cursos na modalidade BolsaFormação no período de 2011 a maio de 2014 (ver quadro 1).

\section{Quadro 1: Número absoluto de beneficiários do Pronatec Bolsa-Formação, distribuídos por parceiros ofertantes (2011 - maio 2014)}

\begin{tabular}{|l|l|l|r|r|r|r|r|}
\hline Ranking & $\begin{array}{l}\text { Parceiros } \\
\text { Ofertantes }\end{array}$ & $\begin{array}{l}\text { Natureza } \\
\text { das Redes } \\
\text { Ofertantes }\end{array}$ & $\begin{array}{c}\text { Cursos } \\
\text { FIC }\end{array}$ & $\begin{array}{r}\text { Cursos } \\
\text { Técnicos }\end{array}$ & $\begin{array}{c}\text { Total } \\
\text { Geral }\end{array}$ & $\begin{array}{c}\text { Valores } \\
\text { recebidos por } \\
\text { rede de ensino }\end{array}$ & $\%$ \\
\hline $\mathbf{1}^{\mathbf{0}}$ & SNA & Privada & 1.975 .193 & 253.034 & 2.228 .227 & $4.528 .266 .363,68$ & 70,15 \\
\hline $\mathbf{2}^{\mathbf{0}}$ & $\begin{array}{l}\text { Rede } \\
\text { Federal }\end{array}$ & Pública & 425.482 & 21.831 & 447.313 & $1.315 .043 .126,95$ & 20,3 \\
\hline $\mathbf{3}^{\circ}$ & $\begin{array}{l}\text { Rede } \\
\text { Estadual }\end{array}$ & Pública & 99.038 & 54.277 & 153.315 & $404.523 .150,00$ & 6,2 \\
\hline $\mathbf{4}^{\circ}$ & $\begin{array}{l}\text { Instituições } \\
\text { Privadas }\end{array}$ & Privada & - & 292.550 & 292.550 & $189.794 .626,64$ & 3 \\
\hline $\mathbf{5}^{\circ}$ & $\begin{array}{l}\text { Rede } \\
\text { Municipal }\end{array}$ & Pública & - & 462 & 462 & $18.061 .000,00$ & 0,35 \\
\hline \multicolumn{3}{|l|}{ TOTAL GERAL } & $\mathbf{2 . 4 9 9 . 7 1 3}$ & $\mathbf{6 2 2 . 1 4 5}$ & $\mathbf{3 . 1 2 1 . 8 6 7}$ & $\mathbf{6 . 4 5 5 . 6 8 8 . 2 6 7 , 2 7}$ & $\mathbf{1 0 0}$ \\
\hline
\end{tabular}

Fonte: Souza, 2017

Foram registrados mais de três milhões de beneficiários da BolsaFormação. Do total das bolsas ofertadas, os cursos FIC contemplaram 2.499.713 bolsistas (80\%), um quantitativo bem superior se comparado ao dos cursos técnicos, que concederam 622.145 bolsas (20\%).

Salta-nos aos olhos a majoritária participação das instituições da rede privada. Juntas, elas receberam 2.520 .777 bolsas, aproximadamente $81 \%$, enquanto a rede pública (federal, estadual e municipal) recebeu apenas $19 \%$ do total da oferta da Bolsa-Formação.

Quanto aos valores investidos de 2011 a maio de 2014, o FNDE transferiu mais de seis bilhões de reais, com destaque para a rede privada, que recebeu $73 \%$ das vagas, ou seja, 4,7 bilhões de reais, enquanto a rede pública recebeu apenas 1,7 bilhão de reais. Levando em consideração apenas a Bolsa-Formação, é possível afirmar que o SNA foi a unidade que mais recebeu os recursos do programa, mais de $70 \%$, o equivalente a aproximadamente $\mathrm{R} \$ 4,5$ bilhões de reais.

Também é importante registrar que, de 2011 a maio de 2014, a rede privada e as unidades do Sistema S foram responsáveis por $87,7 \%$ das matrículas, enquanto a rede pública (federal, estadual e municipal) efetuou apenas $12,3 \%$ do total das matrículas dos cursos técnicos. 
Cabe destacar, ainda, que uma das nove ações do Pronatec é o "incentivo à ampliação de vagas e à expansão da rede física de atendimento dos serviços nacionais de aprendizagem" (BRASIL, 2011) ${ }^{15}$. Essa ampliação vem sendo realizada com fontes de financiamento vindas do Banco Nacional de Desenvolvimento Econômico e Social (BNDES).

Neste estudo, examinamos esse programa demonstrando seus limites. Dentre eles, o seu caráter privatista ao adotar o formato de parceria com instituições ofertantes do Pronatec/Bolsa-formação. Cabe, ainda, considerar que

\begin{abstract}
além do Sistema $S$, as empresas privadas que atuam no ensino encontram no Pronatec o alento para a manutenção dos seus negócios, mediante financiamento dos cursos a serem ofertados aos trabalhadores e estudantes, desde que habilitadas pela comissão avaliadora constituída em cada instituto federal de educação, ciência e tecnologia. Para melhor perceber a dimensão desse tipo de financiamento, vale registrar o fato de que, somente no ano de 2012, de acordo com o relatório da gestão do MEC, foram habilitadas 339 unidades de ensino, sendo que 85 são privadas e 254 do Sistema S. (OLIVEIRA; MENEZES, 2016, p. 231).
\end{abstract}

Apesar de o Pronatec oferecer cursos técnicos de nível médio, $70 \%$ do total das vagas ofertadas privilegiam os cursos FIC, modelo de formação aligeirada que não exige uma qualificação complexa. $O$ que significa dizer que $o$ Pronatec, por meio da política de parcerias, transfere os recursos públicos e privilegia as instituições privadas, especialmente o Sistema $\mathrm{S}$, responsável por $70 \%$ das matrículas nos cursos $\mathrm{FIC} \mathrm{e} 40 \%$ nos cursos técnicos.

A priorização num modelo de qualificação profissional de curta duração, que restringe $\mathrm{o}$ acesso às bases mais amplas do conhecimento científico e tecnológico, é uma das principais continuidades dos programas Programa Intensivo de Preparação de Mão de Obra (PIPMO), Plano Nacional de Qualificação do Trabalhador (Planfor) e Programa Nacional de Qualificação Social e Profissional $(\mathrm{PNQ})^{16}$ em relação ao Pronatec. Em suma, ele "veste o presente

\footnotetext{
${ }^{15}$ Sublinhamos que a participação do Sistema $S$ na oferta de cursos voltados para a Educação Profissional não é exclusividade do Pronatec. Isso ocorre desde a década de 1960, em que o Sistema S participou da execução do Programa Intensivo de Preparação da Mão de Obra (PIPMO) de 1963 a 1982.

${ }^{16}$ Em vigência de 2003 a 2007.
} 
com roupagens emprestadas de um passado no qual engendraram determinações regressivas à extensão do direito à educação para os jovens e adultos trabalhadores" (MACHADO; GARCIA, 2013, p. 3).

Além da Bolsa-Formação, o SNA ainda recebe recursos do Acordo Gratuidade e do Fies. Os documentos oficiais não apresentam um detalhamento dos recursos recebidos por essas ações, o que dificulta uma análise crítica das especificidades de cada um deles e dos valores reais transferidos às redes pública e privada.

A Bolsa-Formação foi a única ação que teve a prestação de contas disponibilizada pela SETEC no Relatório de Auditoria Anual de Contas de 2013 (BRASIL, 2013a). Limitamo-nos, por esse motivo, a apresentar informações particulares apenas dessa modalidade.

Grosso modo, é possível afirmar que a expansão da educação profissional por meio do Pronatec vem ocorrendo sob a lógica da privatização, em que o Governo Federal transfere, por meio de recursos públicos, as responsabilidades pela oferta pública e gratuita às instituições privadas, sendo o principal exemplo desse tipo de privatização o Serviço Nacional de Aprendizagem.

Essa forma de gestão e execução deve ser questionada, assim como o modelo de formação ofertado aos jovens e adultos trabalhadores, já que o programa prioriza a oferta de cursos FIC e de cursos técnicos na modalidade concomitante e subsequente. Essa conformação inviabiliza o fortalecimento do ensino integrado e da formação humana integral, retomando a proposta original do decreto no 2.208/97 (BRASIL, 1997), que instituiu a separação entre a educação básica e a educação profissional (LIMA, 2012).

A efetivação de cursos técnicos integrados nas redes públicas demandaria maiores investimentos com estrutura física, material didático, contratação de professores e de outros profissionais. Dessa forma, é mais vantajoso, de certo modo, para a sociedade civil e para a sociedade política ${ }^{17}$, expandir a qualificação profissional por meio da ampliação de vagas na rede privada do que expandir a estrutura física da rede pública. A compra de vagas na rede privada pelo Governo

\footnotetext{
${ }^{17}$ Considerando que, para Gramsci (2007, p. 244), "na noção geral do Estado entram elementos que devem ser remetidos à noção de sociedade civil" e é através dele que a classe dirigente justifica e mantém o seu domínio.
} 
Federal ocorre por meio da transferência de recursos públicos através da BolsaFormação, do Acordo Gratuidade Sistema S e do Fies Técnico e Empresa.

Além disso, a formação aligeirada também propicia um menor custo, o que legitima o aumento da oferta de cursos FIC em relação aos cursos técnicos no programa, favorecendo 0 processo de privatização do bem público e 0 financiamento do empresariado na formação dos seus empregados.

Em suma, o Pronatec se configurou como uma política de qualificação desqualificadora que serviu mais aos ofertantes dos cursos em disputa pelos vultosos fundos públicos do que aos demandantes destes, ou seja, aos trabalhadores e suas necessidades de acesso à educação e à inserção profissional.

\section{Considerações Finais}

O estudo empreendido nos possibilita afirmar que o Pronatec, enquanto uma política de qualificação da classe trabalhadora que não pretende viabilizar o acesso aos níveis mais elevados de escolarização, desenvolve-se a partir do papel subordinado do país na divisão internacional do trabalho.

É importante registrar que a análise não deixa dúvidas quanto aos limites desse programa, tanto em elevar os níveis de escolarização da classe trabalhadora quanto em contribuir para a melhoria da qualidade do Ensino Médio; bem como em ampliar as oportunidades de acesso à qualificação e ao emprego; e, ainda, em estimular a articulação entre a política de educação profissional e tecnológica e as políticas de geração de trabalho, emprego e renda.

$\mathrm{Na}$ tentativa de explicitar esses limites, nossa exposição dividiu-se em duas partes. Na primeira, procuramos descrever com densidade a proposta do Pronatec, salientando sua formulação oficial e os dados sobre sua execução. Além de fazer o registro histórico de mais um programa federal, buscamos, de forma crítica, evidenciar a intrincada engenharia desse programa guarda-chuva, que abriga, atualmente, quase todos os programas e projetos anteriores, reagrupados gradativamente por ele.

Na segunda parte, a análise permitiu afirmar que, na oferta da qualificação profissional do Pronatec, por um lado, predomina a formação para o trabalho 
simples - como a expressiva oferta de cursos FIC evidencia - e, por outro, a ampliação da privatização da educação profissional, no tratamento dado à qualificação como serviço e como mercadoria.

A expansão da qualificação profissional realizada pelo Pronatec, com ênfase na realização de cursos FIC por instituições privadas, não deixa dúvidas de que esse programa, inspirado nos preceitos neoliberais, ao renovar a dualidade estrutural da educação brasileira, não só estimulou a expansão do mercado educacional, como também se adequou às demandas do capital na renovada subalternidade do país nas relações econômicas internacionais.

Sob o discurso inclusivo, o Pronatec reedita o modelo de qualificação restrita à adaptação para e pelo mercado, em que a educação profissional é vista como uma mercadoria a ser vendida e consumida pela classe trabalhadora como condição de acesso ao emprego.

Assinalamos, pois, o quanto ele representa, por um lado, a continuidade de uma visão de que a educação possa ser feita por meio de programas contingentes e, por outro, a ampliação dos mecanismos de destinação de recursos financeiros públicos para apoiar a oferta de cursos no âmbito das instituições privadas.

Essa atuação revela que o Pronatec atua na (con)formação da classe trabalhadora em tempos neoliberais. Reiteramos, portanto, que a expansão aligeirada e fragmentada da qualificação profissional para o emprego realizada pelo Pronatec vem se constituindo como um importante instrumento de legitimação da sociabilidade neoliberal, que subordina a formação humana aos estreitos nexos da concepção mercantilista de educação.

Tal processo não é recente. Desde meados da década de 1990, recorrentemente, sob o discurso de ampliação das oportunidades educacionais, são oferecidos programas educacionais aligeirados, de caráter compensatório e emergencial. Eles apresentam como características comuns: cursos que exigem baixos níveis de escolarização, oferta fragmentada, descontinuidade e pulverização de recursos via parcerias do público com o privado.

Assim como os anteriores, o Planfor, o PNQ, o Projovem e o Programa Nacional de Integração da Educação Profissional com a Educação Básica na 
Modalidade de Educação de Jovens e Adultos (Proeja) ${ }^{18}$, o Pronatec reitera a perspectiva que relaciona a educação ao desenvolvimento e à competitividade do país e atribui à educação a função de promover a equidade e a contenção social, de ensinar e difundir o empreendedorismo, marcas da perspectiva economicista de educação. Afirmamos, portanto, que o Pronatec - que tem um papel central na política de educação profissional atualmente - nada mais é do que uma continuidade piorada dos programas anteriores. Nas palavras de Lima (2016, p.115):

no decorrer do governo Dilma (2010-2014), percebe-se com a emergência do Pronatec, o esvaziamento da pedagogia do PROJOVEM e do PNQ e a pequena oferta do PROEJA FIC e, mesmo, do PROEJA Técnico um processo de desintegração curricular que tem resultado num afastamento ainda maior entre as políticas de educação de jovens e adultos e de qualificação profissional.

Esse movimento da realidade da educação profissional representa um recuo em relação aos programas citados (PROJOVEM, PNQ, PROEJA FIC E PROEJA Técnico) que apesar de suas deficiências constituíam um avanço em relação à política do decreto $n^{0} 2208$ de 1997 e à pedagogia do Planfor.

Evidenciamos, também, o caráter privatista do programa que, ao adotar o formato de parceria com instituições ofertantes do Pronatec/Bolsa-formação, vem transferindo, regularmente, recursos públicos para instituições privadas e intensificando o processo de privatização da educação profissional, com especial destaque para o Sistema S.

Por fim, a última consideração diz respeito a um ponto ainda pouco debatido criticamente, que, talvez, ajude-nos a aprofundar nossa compreensão sobre a dinâmica das contradições do real no caso do Pronatec: a potencialidade que o programa tem de alterar positivamente as chances dos jovens e adultos na luta pela sobrevivência material imediata.

Apesar dos seus limites, o programa é importante para uma parcela significativa dos jovens e adultos trabalhadores. Justo porque alimenta esperança, porque potencializa, ainda que precariamente, a entrada no mundo do trabalho

\footnotetext{
${ }^{18}$ O Proeja foi criado no ano de 2005.
} 
em uma posição menos perversa do que aquela em que o indivíduo já se encontra e porque pode garantir a migração para programas assistenciais de renda mínima. O que, em muitos momentos, é crucial para que essas pessoas continuem sobrevivendo com o mínimo de dignidade.

Fato é que o Pronatec, ao ter como público-alvo prioritário as pessoas em situação de vulnerabilidade e risco social, apresenta-se para essas frações da classe trabalhadora - sobre as quais ainda incidem diversas outras formas de exploração e opressão - como uma oportunidade, às vezes a única, de acesso a algum tipo de certificação profissional. Mesmo sem pretender viabilizar o acesso aos níveis mais elevados de escolarização, o Pronatec expandiu a possibilidade de uma grande parcela da população obter alguma qualificação com certificação profissional.

No bojo dessas contradições, reafirmamos que esse movimento precisa ser problematizado. Ainda que haja a clareza de que a formação da classe trabalhadora executada dessa maneira reitera, através do Pronatec, o velho discurso da qualificação como potencializadora de acesso à educação e ao emprego que, ao mesmo tempo, amplia significativamente o repasse de recursos públicos às instituições privadas.

Por tudo isso, o cenário exige que se reafirme a concepção de formação humana integral. Como dizem Melo e Moura (2016, p. 117), é "na disputa por uma concepção de formação humana e de expansão da EP [Educação Profissional] diferentes das que estão postas no Pronatec que se poderá questioná-lo e, em alguma medida, contribuir para sua ressignificação".

Exige, também, que pleiteemos uma educação fundamentalmente distinta da que vivemos hoje. Uma educação pensada a partir das perspectivas dos trabalhadores; ofertada e garantida pelo Estado de forma gratuita, pública, unitária e desinteressada.

Refletir sobre a qualificação do ponto de vista dos trabalhadores, a nosso ver, é afirmar a educação, em todas as suas dimensões e espaços, como um processo social formador de todas as dimensões do ser humano. Um processo social voltado para a necessidade de uma escola de natureza científicotecnológica para todos, em todos os níveis e ramos de ensino, a partir do horizonte da educação emancipadora. 


\section{Referências}

BRASIL. Controladoria Geral da União. Secretaria de Educação Profissional e Tecnológica. Relatório de Auditoria Anual de Contas 2013. Brasília, CGU, SETEC, 2013a. Disponível em: http://portal.mec.gov.br/index.php?option=com_docman\&view= download\&alias $=16416$-setec-relatorio-de-auditoria-certificado-e-parecerexercicio-2013\&category_slug=setembro-2014-pdf\&ltemid=30192>. Acesso em: 02 abr. 2017.

. Decreto $n^{\circ} 2.208$, de 17 de abril de 1997. Brasília: Presidência da República, 1997. Disponível em: <http://www.planalto.gov.br/ccivil_03/decreto/d2208.htm>. Acesso em: 23 fev. 2018.

. Decreto no 5.154, de 23 de julho de 2004. Brasília: Presidência da República, 2004. Disponível em: <http://www.planalto.gov.br/ccivil_03/_ato20042006/2004/decreto/d5154.htm>. Acesso em: 23 fev. 2018.

. Lei 7.998, de 11 de janeiro de 1990. Brasília: Presidência da República, 1990. Disponível em: <http://www.planalto.gov.br/ccivil_03/leis/L7998.htm>. Acesso em: 23 fev. 2018.

. Lei no 8.212, de 24 de julho de 1991. Brasília: Presidência da República, 1991. Disponível em: <http://www.planalto.gov.br/ccivil_03/leis/L8212cons.htm>. Acesso em: 23 fev. 2018.

\section{1.} . Lei 10.260, de 12 de julho de 2001. Brasília: Presidência da República, fev. 2018.

- Lei no 11.129, de 30 de junho de 2005. Brasília: Presidência da República, 2005. Disponível em: <http://www.planalto.gov.br/ccivil_03/_ato20042006/2005/lei/l11129.htm>. Acesso em: 23 fev. 2018.

. Lei no 12.513, de 26 de outubro de 2011. Brasília: Presidência da República, 2011. Disponível em: <http://www.planalto.gov.br/ccivil_03/_ato20112014/2011/lei/l12513.htm>. Acesso em: 23 fev. 2018.

. Lei no 12.816, de 5 de junho de 2013. Brasília: Presidência da República, 2013b. Disponível em: <http://www.planalto.gov.br/ccivil_03/_ato20112014/2013/Lei/L12816.htm>. Acesso em: 23 fev. 2018.

. Medida Provisória $n^{\circ}$ 593, de 5 de dezembro de 2012. Brasília:

Presidência da República, 2012a. Disponível em:


<http://www.planalto.gov.br/ccivil_03/_ato2011-2014/2012/Mpv/593.htm>. Acesso em: 23 fev. 2018.

Ministério da Educação. Programa Nacional de Acesso ao Ensino Técnico e Emprego. Documento referência para a Bolsa-Formação trabalhador no âmbito do Pronatec. Brasília: MEC, Pronatec, 2012b. Disponível em: $<$ http://www.ifrs.edu.br/site/midias/arquivos/2013021105817732documento referencia_bolsa_formacao_trabalhador.pdf>. Acesso em: 23 fev. 2018.

Ministério da Educação. Programa Nacional de Acesso ao Ensino Técnico e Emprego. Guia Pronatec de Cursos FIC. 3. ed. Brasília: MEC, Pronatec, 2013c. Disponível em: $<$ http://www.ifrs.edu.br/site/midias/arquivos/20138248933591guia_pronatec_de_c ursos_fic_3a._edicao_-_portaria_mec_899-2013.pdf>. Acesso em: 23 fev. 2018.

$\begin{array}{cccc}\text { Pertaria } n^{\circ} \text { 114, de } 7 \text { de fevereiro de 2014. Brasília: Presidência da } & \\ \text { República, } & 2014 . & \text { Disponível }\end{array}$ $<$ http://pronatec.mec.gov.br/images/stories/pdf/portaria_114.pdf>. Acesso em: 23 fev. 2018.

República, 2013d. Disponível em: <http://pronatec.mec.gov.br/images/stories/pdf/port_168_070313.pdf>. Acesso em: 23 fev. 2018.

República, 2012c. Disponível em: $<$ http://pronatec.mec.gov.br/images/stories/pdf/portaria_185.pdf>. Acesso em: 23 fev. 2018.

Secretaria de Educação Profissional e Tecnológica. Relatório de Gestão do Exercício de 2013. Brasília: MEC, SETEC, 2013e. Disponível em: $<$ http://portal.mec.gov.br/index.php?option=com_docman\&view=download\&alias= 15996-relatorio-gestao-exercicio-2013-setec-pdf\&ltemid=30192>. Acesso em: 23 fev. 2018.

. Secretaria de Educação Profissional e Tecnológica. Relatório de Lançamentos de Estudos. Brasília: MEC, SETEC, 2015. Disponível em: $<$ http://portal.mec.gov.br/index.php?option=com_docman\&view=download\&alias= 22071-24092015-lancamento-estudos-pronatec-setec-pdf\&category_slug=abril2010-pdf\&ltemid=30192>. Acesso em: 23 fev. 2018.

FONTES, Virgínia. O Brasil e o capital imperialismo: teoria e história. Rio de Janeiro: EPSJV/Editora UFRJ, 2010.

FRIGOTTO, Gaudêncio. A produtividade da escola improdutiva: um (re)exame das relações entre educação e estrutura econômico-social e capitalista. São Paulo: Cortez, 1993. 
A relação da educação profissional e tecnológica com a universalização da educação. Educação \& Sociedade, Campinas, v. 28, n. 100, edição especial, p. 1129-1152, out. 2007.

. Juventude, trabalho e educação: o presente e o futuro interditados em suspenso. In: TIRIBA, Lia; CIAVATTA, Maria (Orgs.). Trabalho e educação de jovens e adultos. Brasília: Liber Livro e Editora UFF, 2011.

FRIGOTTO, Gaudêncio; CIAVATTA, Maria; RAMOS, Marise. A política de educação profissional no governo Lula: um percurso histórico controvertido. Educação \& Sociedade, Campinas, v. 26, n. 92, edição especial, p. 1087-1113, out. 2005.

GRAMSCI, Antonio. Maquiavel, a política e o Estado moderno. 3. ed. v. 3. Rio de Janeiro: Civilização Brasileira, 2007.

LIMA, Marcelo. Problemas da Educação Profissional do Governo Dilma: Pronatec, PNE e DCNEMs. Trabalho \& Educação, Belo Horizonte, v. 21, n. 2, mai./ago. 2012, p. 73-91.

- Trabalho e Educação no Brasil: da formação para o mercado ao mercado da formação. Curitiba: CRV, 2016.

MACHADO, Maria Margarida; GARCIA, Lênin Tomazett. Passado e presente na formação de trabalhadores jovens e adultos. Revista Brasileira de Educação de Jovens e Adultos, v. 1, n. 1, p. 45-64, 2013.

MELO, Ticiane Gonçalves Sousa de; MOURA, Dante Henrique Moura. Programa Nacional de Acesso ao Ensino Técnico e Emprego (Pronatec): expansão e privatização da educação profissional. Holos, Ano 32, v. 6, 2016, p. 103-119.

OLIVEIRA, Dalila Andrade de. Educação básica: gestão do trabalho e da pobreza. Rio de Janeiro: Vozes, 2000.

OLIVEIRA, Elenice Gomes de; MENEZES, Rommel Rennê Santos de. Desafios e contradições do Programa nacional de acesso ao ensino técnico e médio (Pronatec). In: SOUZA, Antônia de Abreu; OLIVEIRA, Elenice Gomes de; NETO, Eneas de Araújo Arraias. As interfaces do mundo do trabalho: educação, práxis social e formação dos trabalhadores. Curitiba: CRV, 2016.

RODRIGUES, José. Os empresários e a educação superior. Campinas: Autores Associados, 2007.

RUMMERT, Sonia Maria; ALGEBAILE, Eveline; VENTURA, Jaqueline. Educação da classe trabalhadora brasileira: expressão do desenvolvimento desigual e combinado. Revista Brasileira de Educação, v. 18 n. 54, p. 717-738, jul.-set. 2013.

SANTOS, Thayane da Costa Campos. Educação profissional em cena: uma análise do programa nacional de acesso ao ensino técnico e emprego (Pronatec) 
e suas implicações para a formação humana. 2014. 185 f. Dissertação (Mestrado em Educação) - Universidade Federal de Juiz de Fora, Juiz de Fora.

SILVA, Maria Izabel Costa da. Pronatec e as artes de governar: capturas e apropriações em uma Escola Federal do Espírito Santo Vitória. 2015. 234 f. Dissertação (Mestrado em Psicologia) - Universidade Federal do Espírito Santo, Vitória.

SILVA, Lucilia Carvalho de. A entrada dos trabalhadores nos Institutos Federais pela via dos cursos de formação inicial e continuada: uma análise sobre a educação dos mais pobres. 2014. 354 f. Tese (Doutorado em Educação) Universidade Federal Fluminense, Niterói.

SOUZA, Samantha Castro Vieira de. Pronatec e a (con)formação da classe trabalhadora em tempos neoliberais. 2017. 234 f. Dissertação (Mestrado em Educação) - Universidade Federal Fluminense, Niterói.

VENTURA, Jaqueline; LESSA, Ludmila Lustosa; SOUZA, Samantha Castro Vieira de. O PRONATEC e a (con)formação do trabalhador: a privatização da educação profissional e o rebaixamento da formação humana. In: BOMFIM, Maria Inês; RUMMERT, Sonia Maria. Educação de Jovens e Adultos da Classe Trabalhadora Brasileira: "Novos" projetos e antigas disputas. Curitiba: CRV, 2017.

Recebido em: 05 de março de 2018. Aprovado em: 09 de maio de 2018. Publicado em: 21 de novembro de 2018. 